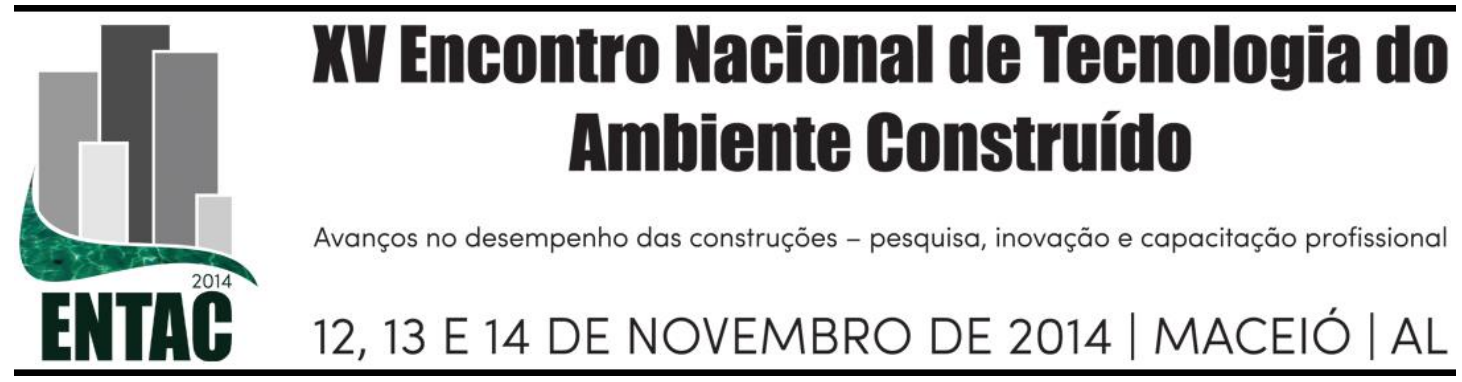

\title{
QUALIDADE DA ADESÃO DA MADEIRA DE PINUS E EUCALIPTO PARA PRODUÇÃO DE PAINÉIS ESTRUTURAIS CROSS LAMINATED TIMBER (CLT)
}

\author{
ALENCAR, Juliana Bello Mussi (1); MOURA, Jorge Daniel de Melo (2); \\ (1) Universidade Estadual de Londrina- UEL, (43) 3371-4000, e-mail: juliana_mussi@ hotmail.com (2) \\ Universidade Estadual de Londrina, e-mail: jordan@uel.br
}

\begin{abstract}
RESUMO
O Sistema Construtivo Cross Laminated Timber ou CLT (madeira laminada cruzada), desenvolvido primeiramente na Áustria e Alemanha, tem despontado recentemente como uma excelente alternativa para a construção civil. A região de Telêmaco Borba-PR possui uma indústria de serraria que produz uma grande quantidade de peças de madeira de baixo valor agregado, como peças de pequeno comprimento de Pinus e peças provenientes da região da medula do Eucalipto, materiais utilizados na pesquisa. $\mathrm{O}$ objetivo deste trabalho é a análise da qualidade e desempenho de colagem através de testes em corpos de provas, utilizando tábuas de madeira de reflorestamento, Pinus spp e Eucalipto grandis, previamente classificadas visual e mecanicamente, para futura utilização em painéis estruturais em CLT. De acordo com os conceitos de pesquisa experimental, com objetivos exploratórios, foram testados mecanicamente, conforme a norma NBR 7190/97, 72 corpos de provas representativos de painéis CLT, utilizando os adesivos estruturais Melanina Ureia Formaldeído (MUF) e Ureia-formaldeido (UF). Estes grupos foram subdivididos e colados com orientação paralela e perpendicular as fibras, combinando as espécies pinus e eucalipto. A análise dos resultados obtidos nos testes de determinação da resistência ao cisalhamento longitudinal da colagem entre o pinus e o eucalipto e entre as mesmas espécies, apontou melhor desempenho para o adesivo MUF, nas colagens no sentido paralelo as fibras para a combinação pinus/pinus.
\end{abstract}

Palavras-chave: madeira de reflorestamento, Cross Laminated Timber, colagem de madeira, construção em madeira, estruturas de madeira de reflorestamento.

\begin{abstract}
The Cross Laminated Timber Construction System or CLT (cross laminated timber), first developed in Austria and Germany, has recently emerged as an excellent alternative for construction. The Telêmaco Borba-PR industry has a sawmill that produces a lot of pieces of wood of low value, such as pieces of short lengths of pine and pieces from the bone marrow of Eucalyptus, materials used in the research area. The objective of this study is to examine the quality and performance bonding through tests on test samples using wooden planks reforestation, Pinus spp and Eucalyptus grandis, previously classified visually and mechanically, for future use in structural panels in CLT. According to the concepts of experimental research with exploratory objectives were tested mechanically, according to NBR 7190/97, 72 specimens of representative evidence of CLT panels using structural adhesives Melamine Urea Formaldehyde (MUF) and Urea-formaldehyde (UF). These groups were subdivided and bonded with parallel and perpendicular fibers, combining pine and eucalyptus species. The results obtained in the tests for determining the resistance to longitudinal shear bonding between the pine and eucalyptus trees and between the same species, showed better performance for the MUF adhesive, the collages in the direction parallel to the fibers pine / pine combination.
\end{abstract}


Keywords: plantation wood Cross Laminated Timber, wood adhesive, timber construction, timber structures reforestation.

\section{INTRODUÇÃO}

A madeira de reflorestamento pinus e eucalipto como matéria prima para construção civil, normalmente é sub utilizada no Brasil, destinada principalmente como formas temporárias para estruturas de concreto como vigas, lajes e como escoras. Quando se trata de medula de eucalipto e peças resultantes dos cortes de pinus, com comprimentos menores que $120 \mathrm{~cm}$, a destinação para construção civil é praticamente inexistente. Este fato deve-se principalmente à baixa densidade, característica da medula, parte central das toras, tornando este produto, assim como os recortes de pinus, matéria prima destinada a se transformar em carvão e lenha. Portanto, a possibilidade do aproveitamento deste material, medula de eucalipto e recortes de pinus na construção civil é uma forma de baixar custos de produção e agregar valor a esta matéria prima.

O sistema construtivo em madeira, Cross Laminated Timber (CLT) é composto por tábuas coladas em camadas transversais, formando uma placa maciça com características estruturais. Inicialmente desenvolvido na Áustria e Alemanha, na década de 1990, estes painéis têm sido empregados em vários tipos de construções, comerciais e residenciais, com estudos para utilização inclusive em edifícios altos. O CLT pode ser utilizado em construções de forma exclusiva, como estrutura e vedação, bem como em combinação com outros métodos construtivos como concreto e aço, principalmente em prédios de mais de 2 pavimentos.

Segundo RIVERA (2012), tradicionalmente os sistemas de madeira maciça têm usado fibras de madeira orientadas em uma única direção, tanto em aplicações verticais como horizontais. A característica principal dos painéis de CLT é o bom desempenho estrutural em todas as direções, podendo ser considerado como elementos isotrópicos estruturais, pois são construídos por camadas sobrepostas de peças de madeira em direções transversais com o objetivo de aumentar a rigidez e estabilidade. A espessura do painel pode ser de 3 a 10 camadas, como ilustra a figura 1.

\section{Figura 1. Configuração das camadas dos painéis de CLT.}

Fonte: FPInnovation (2011) CLT Handbook

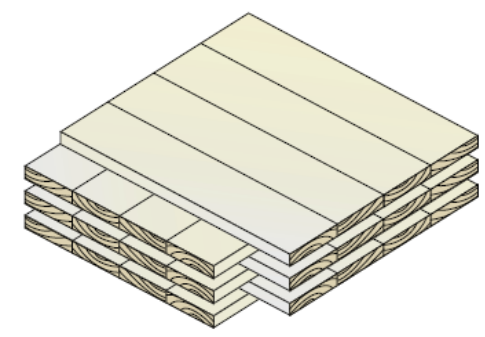

Os painéis podem ser formados com tipos de espécies de madeira diferentes, que podem alterar a sua resistência, aumentando ou diminuindo dependendo das características das espécies. De acordo com a norma ANSI/APA PRG 320 (2011) que regulamenta o CLT nos Estados Unidos, para evitar diferenças nas propriedades físicas e mecânicas da madeira serrada, quando houver combinações de madeira, cada espécie deve ocupar uma camada diferente. A mesma norma estipula uma classificação das espécies disponíveis nos EUA através das resistências físicas e mecânicas, como tensão, flexão, compressão e cisalhamento.

Outro fator que altera a resistência é o tipo de adesivo utilizado na fabricação dos painéis, que de acordo com FPINNOVATIONS (2011) é o segundo componente mais importante do sistema construtivo CLT. Os adesivos utilizados com mais sucesso no CLT são do tipo 
Fenólico: Fenol-resorcinol-formaldeído, Emulsão Polímero Isocianato (EPI) e os Poliuretanos (PUR), no entanto estes adesivos apresentam um custo elevado. Os adesivos estruturais melanina-ureia-formaldeído (MUF) e uréia-formaldeido (UF), por apresentarem menor custo comercial, tornam-se opções viáveis para fabricação de painéis CLT.

De acordo com VITAL et al (2006) dentre as teorias que explicam o fenômeno da adesão, destacam-se a teoria do enganchamento mecânico e da adsorção. Na primeira teoria a penetração do adesivo num substrato poroso leva a formação de ganchos que se prendem nas comadas superficiais da madeira. Segundo a teoria da adsorção a adesão é resultante do contato molecular entre os dois materiais que desenvolvem forças de atração superficiais.

Alguns aspectos interferem no processo de colagem como a variabilidade na densidade e porosidade entre os lenhos iniciais e tardios, cerne e alburno, além da presença de extrativos nas cavidades dos elementos anatômicos. A densidade na madeira indica a quantidade aproximada de espaços vazios disponíveis para receber líquidos, como os adesivos, sendo assim, quanto menor a densidade, maior a permeabilidade na estrutura da madeira formando uma ligação interfacial mais forte entre o adesivo e a madeira (VITAL et al 2006).

O presente estudo teve como objetivo avaliar a qualidade da colagem entre as madeiras de eucalipto e Pinus, provenientes da região da medula, utilizando-se dois adesivos, melaninaureia-formaldeído (MUF) e ureia-formaldeído (UF), em corpos de prova colados em planos paralelos e perpendiculares às fibras.

\section{MATERIAL E MÉTODOS}

O presente trabalho foi desenvolvido no Laboratório de Estruturas do Centro de Tecnologia e Urbanismo da Universidade Estadual de Londrina-Pr. Os corpos de prova para o estudo, foram extraídos de tábuas de madeira serradas das espécies de reflorestamento Pinus spp e Eucalipto grandis, (Tecnomade), provenientes das serrarias da cidade de Telêmaco Borba no Paraná um dos principais produtores de madeira e produtos florestais do estado. A produção da região, se destina na sua maior parte para fabricação de papel e celulose, como cita MOURA et al.(2013).As peças analisadas de medula de Eucalipto são consideradas rejeitos por estas serrarias, pois tem baixo valor comercial, assim como as tabuas de pinus com comprimento abaixo de $120 \mathrm{~cm}$.

Todas as tabuas de medula de eucalipto e pinus foram analisadas visual e mecanicamente, obtendo-se valores de densidade, umidade, Módulo de elasticidade estático e Módulo de elasticidade dinâmico, através de ultrassom. A classificação visual permite estabelecerem-se classes de resistência para o pinus, de acordo com a norma NBR 11700 (1990) e a norma ASTM D245-93.

De acordo com a norma NBR 9487-86 (1986) de classificação de madeira serrada de folhosas, a medula é um defeito considerado inadmissível em qualquer uma das quatro classes, portanto como todas as peças analisadas são compostas em sua maioria por medula, não seria possível sua utilização estrutural. No entanto, tendo como objetivo de agregar valor a estas peças, consideradas rejeitos nas serrarias, e na pretensão de que o impacto deste defeito seja pulverizado na composição de painéis de CLT, as peças foram incluídas no estudo.

Os corpos de prova foram confeccionados livres de defeitos, de acordo com as normas ASTM D 905- 2008 e a NBR 7190-96, com valor de densidade médio de $0,60 \mathrm{~g} / \mathrm{cm}^{3}$ para o eucalipto e $0,61 \mathrm{~g} / \mathrm{cm}^{3}$ para o pinus. Os valores obtidos de MOE estático para o eucalipto foi de $8.342,55 \mathrm{Mpa}$ e de 11.142,14 Mpa para o pinus. As tabuas, tanto de pinus como de eucalipto foram secas em estufa e apresentaram teor de umidade com média de $12 \%$. 
Para confecção dos corpos de prova, as tabuas de pinus e eucalipto, passaram por um processo de aplainamento, para eliminar partículas na superfície da peça e possibilitar a abertura dos poros da madeira, facilitando o processo de penetração do adesivo.

Figura 2. Corpo de prova para a realização do ensaio de cisalhamento da linha de cola (dimensões em mm).

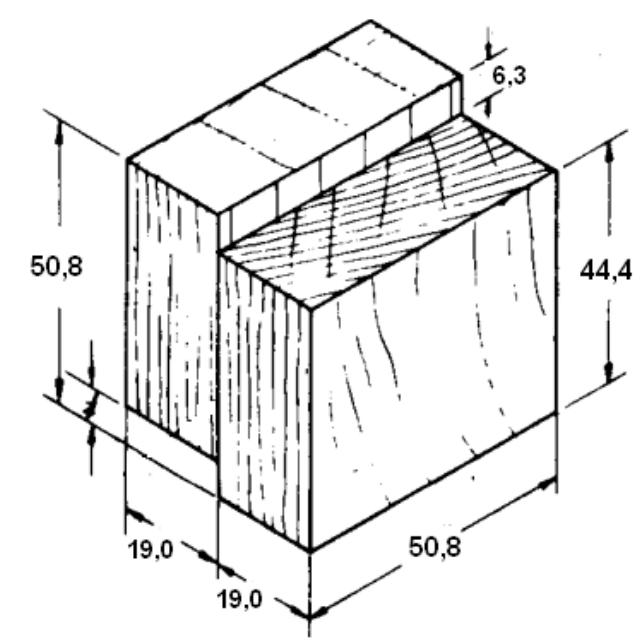

Fonte: ASTM D-905 (ASTM 2008)

Foram elaborados 72 corpos de prova para testes de cisalhamento na linha de cola, dos quais, 36 utilizaram o adesivo estrutural melanina-uréia-formaldeído (MUF), cedido pela empresa Akzonobel e os demais corpos de prova confeccionados com o adesivo estrutural uréiaformaldeído (UF). Além do comparativo entre os adesivos, outro objetivo do estudo é comparar a resistência ao cisalhamento na linha de cola relacionado a direção das fibras e a combinação de espécies como mostra o quadro 1. Serão três grupos diferentes com a combinação de espécies da seguinte forma: pinus/pinus, eucalipto/pinus e eucalipto/eucalipto. Cada grupo será composto de 12 corpos de prova, sendo 6 colados na direção perpendicular às fibras e 6 na direção paralela, com dois tipos de adesivos, MUF e UF.

\section{Figura 2. Orientação das fibras dos corpos de prova para a realização do ensaio de} cisalhamento da linha de cola.
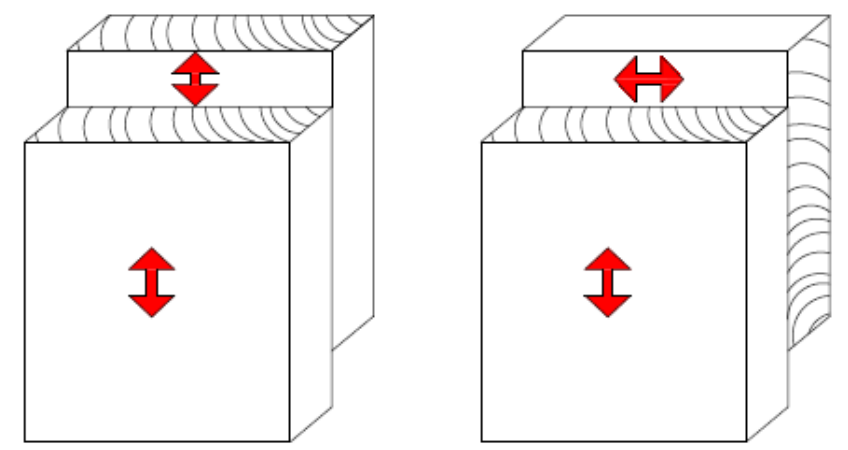

Fonte: Autores.

$\mathrm{O}$ adesivo melanina-ureia-formaldeído (MUF) utilizado em colagens estruturais tem características semelhantes aos do fenol formaldeído, também um bi-componente. A 
gramatura recomendada é de $400 \mathrm{~g} / \mathrm{m}^{2}$ e o tempo de assemblagem é de 50 min a $30^{\circ} \mathrm{C}$ e de 150 minutos a $15^{\circ} \mathrm{C}$. O tempo para prensagem e secagem deve variar de 3 a 10 horas dependendo da temperatura ambiente. A preparação dos corpos de prova com o adesivo MUF, foi realizada utilizando-se para cada 100 partes da resina, 20 partes do catalizador, aplicados com auxilio de uma espátula de silicone. Os corpos de prova foram prensados a frio, com pressão de $0,7 \mathrm{Mpa}$ por um período de 6 horas, conforme recomendações do fabricante.

A preparação do adesivo Uréia-formaldeido, segundo orientações do fabricante, foi a seguinte: 100 partes de adesivo, 20 partes de água, 7 partes de catalizador preparado endurecedor HLE-30 e 20 partes de extensor a base de farinha de trigo. Para melhor visualização e análise da falha na linha de cola, foi adicionado corante (anilina) verde na composição, conforme figura 3. Assim como na aplicação do MUF, a gramatura do adesivo UF foi de $400 \mathrm{~g} / \mathrm{m}^{2}$, com auxilio de uma espátula de silicone. Ainda segundo recomendações do fabricante, os corpos de prova foram prensados a frio com pressão de 1,2 Mpa por um período de 6 horas.

\section{Figura 3. Preparação do adesivo Ureia-formaldeído com adição de corante.}

Fonte: Autores

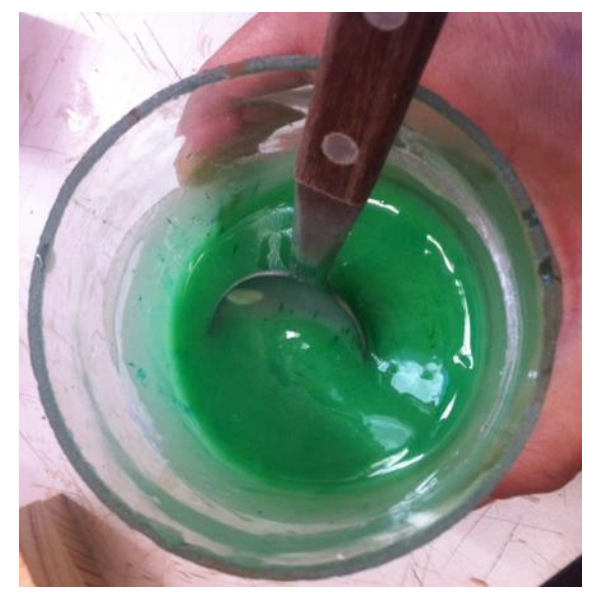

As juntas coladas foram testadas segundo a norma ASTM D-905 (ASTM 2008), por cisalhamento na compressão, como demonstra a figura 4.

Figura 4. Teste de cisalhamento.

Fonte: Autores

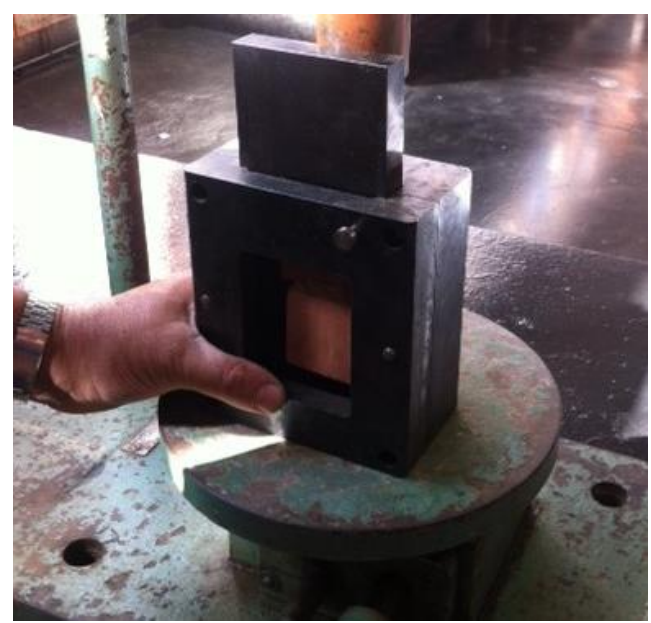


Seguindo as recomendações da literatura, (LOBÃO et al. 2006), após a ruptura, o percentual de falha na madeira das partes do corpo-de-prova foram avaliados com o uso de lâminas transparentes, previamente quadriculadas, e com dimensões que atendessem a variabilidade observada para as dimensões dos corpos de prova. O quadriculado das lâminas dividiu o plano cisalhado em 25 partes, de modo que cada quadrícula representasse $4 \%$ da área em análise. Considerou-se como falha na madeira a fratura profunda, com o arrancamento de partes de madeira, assim como a falha rasa com presença visível de fibras na superfície da ruptura. Após testes de ruptura, 10 corpos de prova, escolhidos aleatoriamente para o processo de secagem em estufa a $60^{\circ} \mathrm{C}$ por um período de 24 horas, para determinação da porcentagem de umidade.

\section{RESULTADOS E DISCUSSÕES}

Os resultados dos ensaios de ruptura nos corpos de prova colados no plano paralelo às fibras são mostrados no quadro 1 .

Quadro 1- Resultados de valores de ruptura obtidos nos testes de cisalhamento dos corpos de prova colados no plano paralelo às fibras.

\begin{tabular}{|l|l|c|c|c|}
\hline Adesivo & \multicolumn{1}{|c|}{ MPa } & pinus /pinus & eucalipto / eucalipto & pinus / eucalipto \\
\hline \multirow{4}{*}{ MUF } & Valor máximo & 24,99 & 24,09 & 21,42 \\
\cline { 2 - 5 } & Valor mínimo & 16,06 & 14,28 & 18,74 \\
\cline { 2 - 5 } & Valor médio & 21,77 & 16,93 & 19,28 \\
\cline { 2 - 5 } & Desvio padrão & 2,84 & 3,29 & 1,36 \\
\cline { 2 - 5 } & CV \% & 13,04 & 19,41 & 7,05 \\
\hline \multirow{4}{*}{ UF } & Valor máximo & 23,02 & 14,99 & 15,88 \\
\cline { 2 - 5 } & Valor mínimo & 15,88 & 6,07 & 6,25 \\
\cline { 2 - 5 } & .Valor médio & 18,92 & 8,71 & 12,14 \\
\cline { 2 - 5 } & Desvio padrão & 3,08 & 3,23 & 3,51 \\
\cline { 2 - 5 } & CV\% & 16,29 & 37,05 & 28,93 \\
\hline
\end{tabular}

Fonte: Autores.

O quadro 1 indica que os corpos de prova colados com o adesivo Melanina-UreiaFormaldeído (MUF) apresentaram valores superiores, em relação ao adesivo Ureiaformaldeído (UF), nos planos de colagem paralelos às fibras. Os maiores valores foram resultantes da colagem do pinus com pinus no plano paralelo as fibras com o adesivo MUF, $15 \%$ superior ao valor médio obtido com o adesivo UF para os corpos de prova de mesma configuração. Nos corpos de prova eucalipto/eucalipto, houve uma diferença de $51 \%$ entre os resultados obtidos nas colagens com adesivo MUF e UF, para os corpos de prova pinus/eucalipto, com o adesivo MUF observou-se valor superior $37 \%$ em relação ao adesivo UF.

Houve uma diferença maior entre os coeficientes de variação (CV\%) para os resultados obtidos nos corpos de prova eucalipto/eucalipto e pinus/eucalipto elaborados com o adesivo UF, em relação aos corpos de prova elaborados com MUF. Para os corpos de prova pinus/pinus, os resultados obtidos foram próximos para os dois adesivos testados, no entanto, maiores para o adesivo MUF, o que pode indicar uma melhor absorção dos adesivos pela madeira pinus em relação ao eucalipto. 
Os resultados dos ensaios de ruptura nos corpos de prova colados no plano perpendiculares às fibras são mostrados no quadro 2.

Quadro 2- Resultados de valores de ruptura obtidos nos testes de cisalhamento dos corpos de prova colados no plano perpendicular às fibras.

\begin{tabular}{|l|l|c|c|c|}
\hline Adesivo & \multicolumn{1}{|c|}{ MPa } & pinus /pinus & eucalipto / eucalipto & pinus / eucalipto \\
\hline \multirow{4}{*}{ MUF } & Valor máximo & 7,14 & 5,71 & 6,07 \\
\cline { 2 - 5 } & Valor mínimo & 5,53 & 3,75 & 4,28 \\
\cline { 2 - 5 } & Valor médio & 6,31 & 4,52 & 5,29 \\
\cline { 2 - 5 } & Desvio padrão & 0,51 & 0,61 & 0,61 \\
\cline { 2 - 5 } & CV \% & 8,08 & 13,42 & 11,47 \\
\hline \multirow{4}{*}{ UF } & Valor máximo & 6,96 & 4,82 & 6,43 \\
\cline { 2 - 5 } & Valor mínimo & 3,57 & 2,14 & 4,46 \\
\cline { 2 - 5 } & .Valor médio & 5,29 & 3,24 & 5,53 \\
\cline { 2 - 5 } & Desvio padrão & 1,16 & 0,85 & 0,64 \\
\cline { 2 - 5 } & CV\% & 22,01 & 26,11 & 11,49 \\
\hline
\end{tabular}

Fonte: Autores.

O quadro 2 mostra que os valores encontrados para os corpos de prova confeccionados no plano perpendicular às fibras variaram $51 \%$ entre o maior e o menor valor, utilizando-se os adesivos MUF e UF, similar a variação encontradas na colagem dos corpos de prova no sentido paralelo às fibras.

Os menores valores obtidos foram resultantes nos grupos de corpos de prova da composição eucalipto com eucalipto, colados no plano perpendicular às fibras com adesivo UF. Corpos de prova colados com adesivo MUF apresentaram valores médios superiores aos colados com UF variando de $12 \%$ a $46 \%$, tanto para colagens no plano paralelo às fibras como para a colagem perpendicular às fibras. Somente no grupo de colagem entre o pinus e eucalipto no plano perpendicular às fibras, o adesivo UF obteve valores médios $5 \%$ superiores ao adesivo MUF. Assim como no resultado das colagens paralelas às fibras, observou-se para os corpos de prova com madeira pinus resultados superiores para os dois adesivos em relação as composições com eucalipto.

As maiores diferenças entre os resultados médios obtidos foram entre os planos de colagens. A direção paralela às fibras atingiu valores médios superiores, entre $53 \%$ a $72 \%$ em comparação aos grupos de corpos de prova colados no plano perpendicular às fibras, como demonstram os quadros 1 e 2. Resultados obtidos por LOBÃO et. al (2006), na comparação entre valores médios de colagem em madeiras com as fibras no sentido perpendicular e paralelo aos esforços foram $41 \%$ maior para o plano colado paralelo às fibras.

O quadro 3 apresenta os resultados observados após analise visual dos corpos de prova rompidos no teste de cisalhamento. 
Quadro 3- Resultados de valores de ruptura obtidos nos testes de cisalhamento dos corpos de prova colados no plano perpendicular às fibras.

\begin{tabular}{|c|c|c|c|}
\hline Plano de colagem & $\begin{array}{l}\text { Combinação de } \\
\text { espécie }\end{array}$ & Adesivo MUF & Adesivo UF \\
\hline \multirow[t]{3}{*}{ Paralelo } & pinus/pinus & $\begin{array}{l}\text { Fratura Profunda 50\% } \\
\text { e Fratura Rasa } 50 \%\end{array}$ & $\begin{array}{l}\text { Fratura Profunda } 45 \% \\
\text { e Fratura Rasa 55\% }\end{array}$ \\
\hline & eucalipto/eucalipto & $\begin{array}{l}\text { Fratura Profunda } 65 \% \\
\text { e Fratura Rasa 35\% }\end{array}$ & $\begin{array}{l}\text { Fratura } \text { Profunda } \\
36 \% \text {, Fratura Rasa } \\
53 \% \text { e falha na linha } \\
\text { de cola } 11 \%\end{array}$ \\
\hline & pinus/eucalipto & \begin{tabular}{lrr} 
Fratura & Profunda \\
(Eucalipto) & $88 \%$ e \\
Fratura & \multicolumn{2}{c}{ Rasa } \\
(Eucalipto) & $12 \%$ \\
\end{tabular} & $\begin{array}{ll}\text { Fratura Profunda } & 20 \% \\
\text { e Rasa } & 20 \% \\
\text { (Eucalipto) } 60 \% & \text { falha } \\
\text { na linha de cola }\end{array}$ \\
\hline \multirow[t]{3}{*}{ Perpendicular } & pinus/pinus & $\begin{array}{l}\text { Fratura Rasa } 95 \% \\
\text { falha na linha de cola } \\
5 \%\end{array}$ & $\begin{array}{l}\text { Fratura Rasa } 42 \% \text { e } \\
\text { falha na linha de cola } \\
68 \%\end{array}$ \\
\hline & eucalipto/eucalipto & $\begin{array}{l}\text { Fratura Profunda } 13 \% \\
\text { Fratura Rasa } 53 \% \text { e } \\
34 \% \text { falha na linha de } \\
\text { cola }\end{array}$ & $\begin{array}{l}\text { Fratura Rasa } 5 \% \text { e } \\
\text { falha na linha de cola } \\
95 \%\end{array}$ \\
\hline & pinus/eucalipto & \begin{tabular}{lrr} 
Fratura & profunda \\
(Eucalipto) & $38 \%$ e \\
Fratura & \multicolumn{2}{c}{ Rasa } \\
(Eucalipto) $62 \%$
\end{tabular} & $\begin{array}{lr}\text { Fratura } & \text { Profunda } \\
\text { (Eucalipto) } & 15 \%, \\
\text { Fratura } & \text { Rasa } \\
\text { (Eucalipto) } & 10 \% \\
\text { Fratura Rasa } & \text { (Pinus) } \\
12 \% \text { e falha na linha } \\
\text { de cola } 63 \%\end{array}$ \\
\hline
\end{tabular}

Fonte: Autores.

A análise visual da ruptura foi realizado de acordo com LOBÃO et. al (2006), após ensaio de ruptura, tanto a fratura profunda como a rasa, assim como a falha na linha de cola. Observouse que, tanto o adesivo MUF como o adesivo UF obtiveram maiores índices de fratura profunda com arrancamento de partes da madeira, principalmente nos planos de colagem paralelo às fibras. Os resultados obtidos para as colagens no plano perpendicular às fibras foram os menos satisfatórios, com fratura rasa na madeira para os corpos de prova confeccionados com MUF e falha na linha de cola para os grupos eucalipto/eucalipto e pinus/eucalipto colados com o adesivo UF, como mostram as figuras 6 e 7. Estes resultados indicam a maior resistência na linha de cola e absorção pela madeira do adesivo MUF, em comparação com a UF, como demostram as figuras 4 e 5 . 
Figuras 4 e 5 - Corpos de prova com adesivo MUF

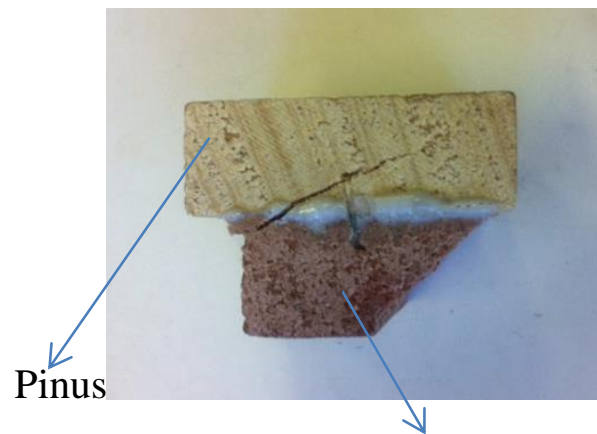

Eucalipto

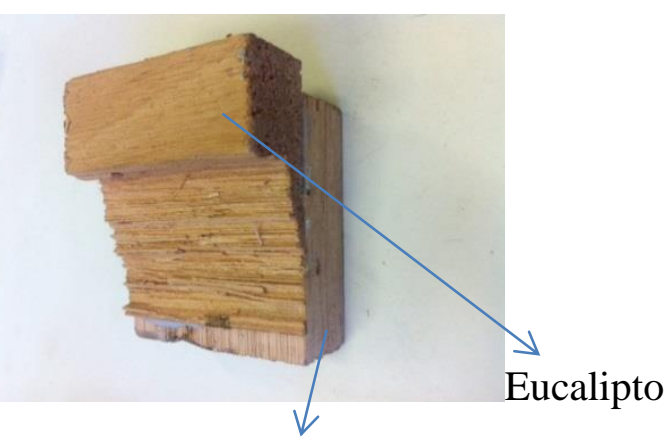

Pinus

Fonte: autores

Figuras 6 e 7 - Corpos de prova com adesivo UF

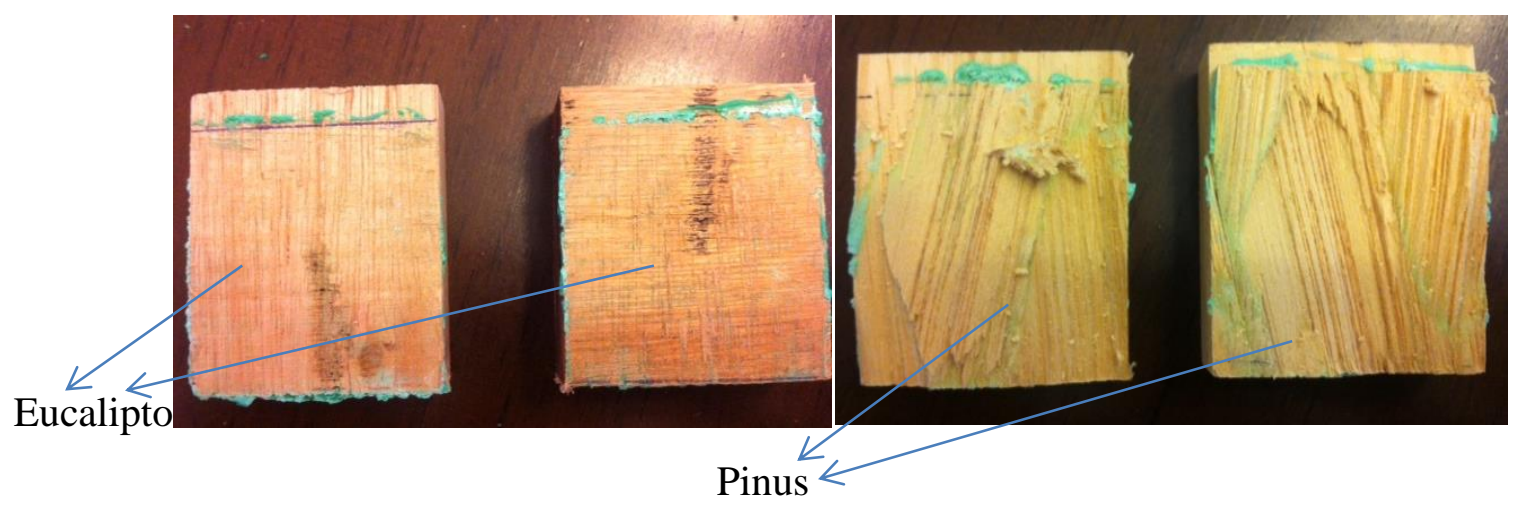

Fonte: autores

A colagem de espécies diferentes, pinus e eucalipto, em todos os corpos de prova, com os dois adesivos, resultaram em fraturas rasas e profundas na madeira de eucalipto, tanto no plano paralelo como no perpendicular às fibras. No entanto, a ocorrência de falha na linha de cola foi observada somente para os corpos de prova de pinus/eucalipto elaborados com o adesivo UF. Estas observações se alinham com as da literatura (LOBÃO et. al 2006), que reporta que elevadas porcentagem de falha na madeira indicam boa qualidade de adesão, no caso deste estudo, a madeira pinus.

\section{CONCLUSÕES}

Através do estudo realizado em corpos de prova confeccionados com Pinus e Eucalipto, colados com adesivos MUF e UF em planos paralelos e perpendiculares às fibras da madeira, os resultados observados foram que o adesivo MUF mostrou-se melhor desempenho em relação ao adesivo UF, nos planos de colagem considerados, paralelo e perpendicular às fibras. Os resultados obtidos neste trabalho mostraram coerência entre aqueles encontrados na literatura o que em hipótese era esperado, tendo em vista estudos que demonstram baixa resistência em lenho juvenil e peças oriundas da área central da tora, neste caso, a medula do eucalipto analisada.

Os valores de cisalhamento nos corpos de prova mostraram que a influência da direção do plano de colagem foi mais importante do que o tipo de adesivo utilizado. Este resultado fica evidente comparando-se os valores médios de todos os grupos de corpos de prova pinus/pinus, eucalipto/eucalipto e pinus/eucalipto, colados nos planos paralelos e colados no plano perpendicular às fibras da madeira. A comparação dos valores obtidos nos testes de 
cisalhamento comprovaram a superioridade do MUF em relação à UF, na ordem de $12 \%$ a $46 \%$.

O adesivo MUF mostrou melhor qualidade de adesão também a partir da análise visual das fraturas nos corpos de prova para todos os grupos analisados. Houve maiores fraturas rasas e falha na linha de cola, principalmente nas composições de corpos de prova com eucalipto utilizando o adesivo UF, o que corrobora a hipótese de uma maior absorção pela madeira com maior porosidade, no caso o pinus. Quanto às falhas na linha de cola, maiores índices foram obtidos nos corpos de prova com UF, principalmente nos grupos eucalipto/eucalipto colados no plano perpendicular às fibras. Neste mesmo grupo, corpos de prova colados com MUF, apresentaram fraturas rasas, evidenciando uma melhor penetração do adesivo MUF em relação ao adesivo UF.

Os dois adesivos utilizados MUF e UF tem valores comerciais próximos, portanto como os resultados obtidos mostraram maior qualidade nas juntas coladas utilizando o adesivo MUF, conclui-se que, para produção de painéis CLT, para o adesivo MUF observou-se maior custobenefício em relação ao adesivo UF.

\section{REFERENCIAS}

AMERICAN SOCIETY FOR TESTING MATERIALS - ASTM. ASTM D 245 - Standard Test Methods for Mechanical Properties of Lumber and Wood-Base Structural Material, Philadelphia, 2002.

AMERICAN SOCIETY FOR TESTING MATERIALS - ASTM. ASTM D 905 - Standard Test Methods for Strength Properties of Adhesive Bonds in Shear by Compression Loading, Philadelphia, 2008.

ASSOCIAÇÃO BRASILEIRA DE NORMAS TÉCNICAS, ABNT, NBR 9487 - Classificação de Madeira Serrada de Folhosas, Rio de Janeiro, 1986, 32 p.

ASSOCIAÇÃO BRASILEIRA DE NORMAS TÉCNICAS, ABNT, NBR 11700 - Madeira serrada de coníferas proveniente de reflorestamento para uso geral, Rio de Janeiro, 1990, 6 p.

APA - THE ENGINEERED WOOD ASSOCIATION. STANDARD FOR PERFORMANCE -Rated Cross-Laminated Timber, ANSI/APA PRG 320. Tacoma, Washington, USA. 2011.

FPINNOVATIONS. CLT Handbook : Cross laminated timber. FPInnovations Canadá. 2011.

LOBÃO, M. S.; GOMES, A.; Qualidade da Adesão de Madeira de Eucalipto em corpos-de-prova colados em dois diferentes Planos de Densidades, 2006, Cerne, Lavras, v. 12, n.2, P. 194-200, abr./jun. 2006

MOURA, J.D.M.; PLETZ, E.; STRASS, M. C.; Panorama Geral e Perspectivas Preliminares de Continuidade dos Trabalhos em Relação às Visitas Técnicas Realizadas a Indústria do Setor Madeireiro do Parque Industrial de Telêmaco Borba a Convite da Secretaria Municipal do Trabalho e Industria Convencional. 2012, Universidade Estadual de Londrina, Relatório Interno.

RIVERA, C.S. Expanding Opportunities for Mid-Rise Buildings in Chile Through the application of Timber Panel Sistems, 2012, (Master of Advanced Studies in Architecture) University of Bristish Columbia - Vancouver 2012.

VITAL, R.B.; MACIEL, A.S.; LUCIA, R.M.D; Qualidade de Juntas coladas com Lâminas de Madeira oriundas de três regiões do tronco de Eucalyptus grandis, Eucalyptus saligna e Pinus elliottii, 2006, Revista Árvore, Viçosa- MG, v.30, n.4, p. 637-644. 